\title{
Patients' Perceptions and Expectations of the General Practice Consultation and of the Doctor's Prioritisation Skills of Multi-Morbidity
}

\section{Carter Singh ${ }^{1-3^{*}}$}

${ }^{1}$ GP Partner Willowbrook Medical Practice, UK

${ }^{2}$ NHS Mansfield \& Ashfield CCG Governing Body GP Board Member, UK

${ }^{3}$ NHS Mansfield \& Ashfield CCG Audit \& Clinical Governance GP Clinical Lead, UK

"Corresponding author: Carter Singh, GP Partner Willowbrook Medical Practice, UK, Tel: 07814737426; E-mail: g777cartersingh@yahoo.co.uk

Received date: January 25, 2017; Accepted date: April 17, 2017; Published date: April 21, 2017

Copyright: $\odot 2017$ Singh C. This is an open-access article distributed under the terms of the Creative Commons Attribution License, which permits unrestricted use, distribution, and reproduction in any medium, provided the original author and source are credited.

\begin{abstract}
Purpose: Patients presenting with multiple problems during a single general practice consultation have been anecdotally referred to as 'shopping list patients'. The aims of this study were to explore the factors that could help general practitioners develop effective strategies to manage these patients.

Methods: This is a questionnaire based study with a total sample size of $(n=66)$. The study timeframe was July 2012 to Jan 2013 and the response rate was $82.5 \%$.

Results: Irrespective of age or gender, most patients admitted to presenting to the GP with multiple problems approximately $30 \%$ of the time. Lack of timely access to GP appointments was the main reason cited by the majority of patients for presenting with multiple problems.

Conclusions: Improving access to GP appointments would reduce patients presenting with multiple problems during a single consultation. The reasons and explanations should be patient centered.

The findings from the research above may facilitate GP's to increase levels of patient/GP satisfaction and safety, optimize rapport, reduce complaints, help to manage time more effectively (reduce late running of appointments) and increase practice productivity.
\end{abstract}

Keywords: General practitioners; Single consultation; Patient knowledge

\section{Introduction}

Patients presenting with multiple problems during a single general practice consultation have been anecdotally referred to as 'shopping list patients'.

The potential complexity in effectively managing these patients has been the topic of both viva exam cases and tea-break discussions amongst general practitioners (GP's) [1,2].

There is no identifiable research analyzing the determinants and circumstances surrounding the reasons why patients present with multiple problems during a single consultation.

Exploring the agendas, ideas, concerns and expectations of 'shopping list patients', could assist general practitioners increase levels of patient/GP satisfaction and safety, optimize rapport, reduce complaints, help to manage time more effectively (reduce late running of appointments) and increase practice productivity [3].

\footnotetext{
Aims

The aims of this study were to explore the factors that could help GP's developed effective strategies to manage 'shopping list patients' [1].
}

The principal areas that were investigated were

(i) Trying to identify if there were any demographic trends amongst 'shopping list patients' i.e. gender, age or presence chronic disease,

(ii) Frequency with which 'shopping list patients' presented with multiple problems,

(iii) Determinants of their presentation with multiple problems,

(iv) The reactions of 'shopping list patients' to being told by their GP that their problems were beyond the scope of one consultation,

(v) Their perceptions of the reasons why some GPs do not deal with every problem they may have during a standard 10 minute consultation,

(vi) The patient's knowledge of the practice policy of booking extended GP appointments [4-7].

\section{Methods}

This is a questionnaire based study in which the determinants and circumstances surrounding the reasons why patients present with multiple problems during a single consultation were explored.

The total sample $(n=66)$ were recruited by one GP distributing the questionnaires to patients after the consultation during which they had presented with three or more problems which were deemed by the GP to be beyond the scope of that consultation [6]. 
Citation: Singh C (20127) Patients' Perceptions and Expectations of the General Practice Consultation and of the Doctor's Prioritisation Skills of Multi-Morbidity. J Gen Pract (Los Angel) 5: 302. doi:10.4172/2329-9126.1000302

Page 2 of 3

A single GP was used to eliminate intra-observer error. The study timeframe was July 2012 to Jan 2013 and the response rate was $82.5 \%$. The study was conducted at a single six-partner GP training practice in Nottinghamshire with a list size of approximately 13000 patients (Figures 1-5).

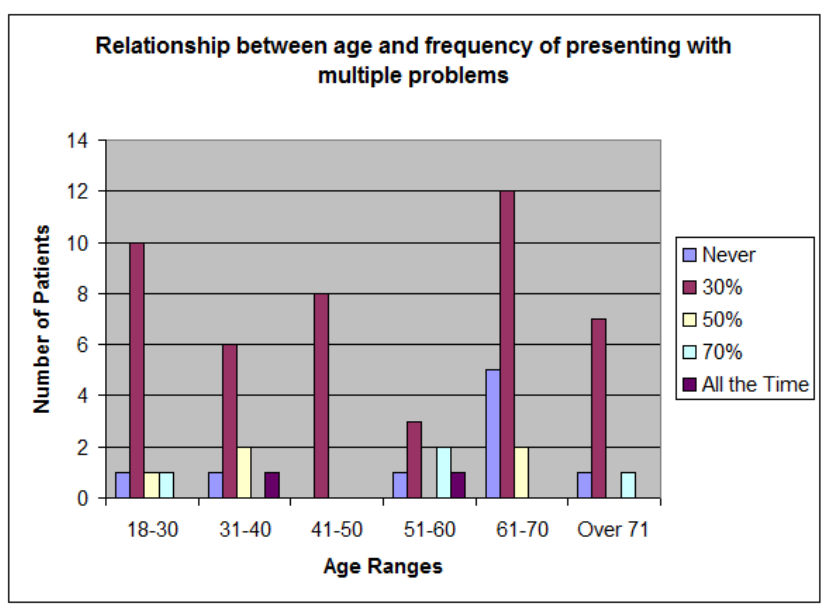

Figure 1: Relationship between age and frequency of presenting with multiple problems.

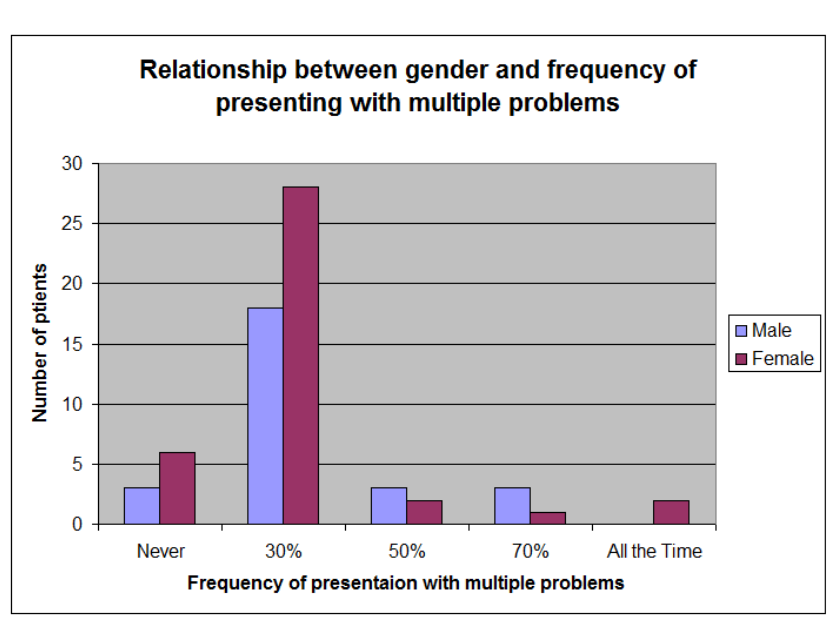

Figure 2: Relationship between gender and frequency of presenting with multiple problems.

Key

a) It took you that long to get an appointment for the original problem that another one developed whilst you were waiting.

b) You feel that unless you present with more than one problem it is not worthwhile 'troubling' the doctor.

c) Your life is that busy that you wait until you have more than one problem until you visit your doctor so that you do not have to attend on multiple occasions. d) It was by chance that you had more than one problem and you believe that it is your GP's duty to deal with all of your problems within the allotted 10 minute time slot.

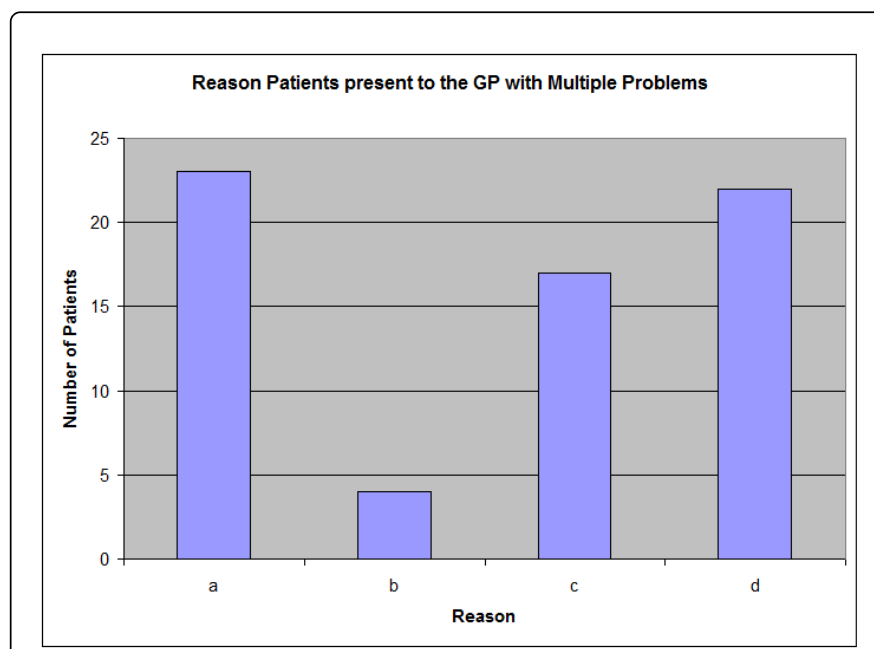

Figure 3: Reason patient to the GP with multiple problems.

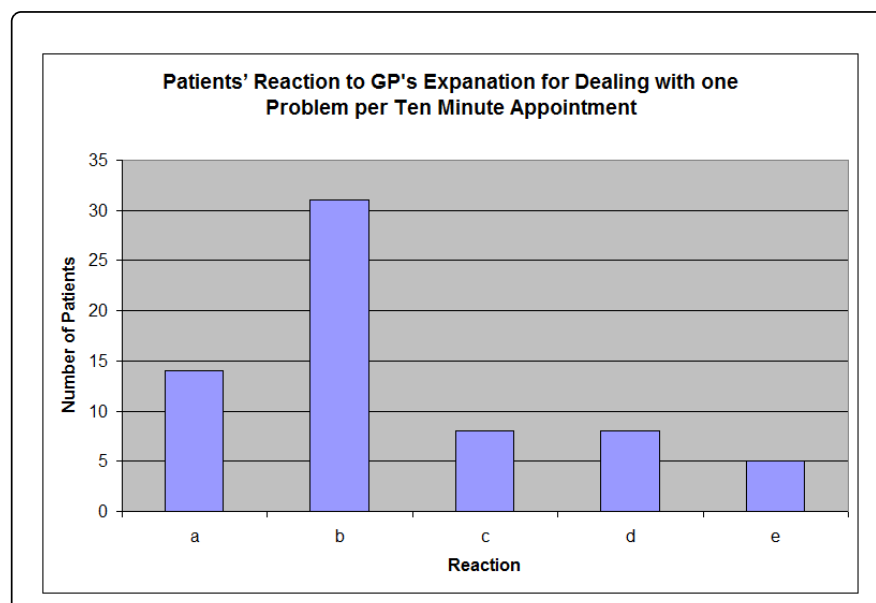

Figure 4: Patients reaction to Gp's explanation for dealing with one problem per 10 minutes appointment.

\section{Key}

a) You would feel angry that all of your problems have not been dealt with.

b) You would understand that the GP has prioritized the most important problem via a discussion with yourself and has explained the reasons behind why he/she cannot effectively deal with all of your problems in a 10 minute appointment.

c) You would feel disappointed that not all of your problems have been dealt with and you would be less likely to see that GP again.

d) You would be dissatisfied with the fact that you would need to return for another appointment and as a result this would cause you significant disruption.

e) You feel that you would rather the GP spend more time addressing all of your problems in one go even if that meant other 
patients would have to wait significantly longer for their appointments as a result of the delay.

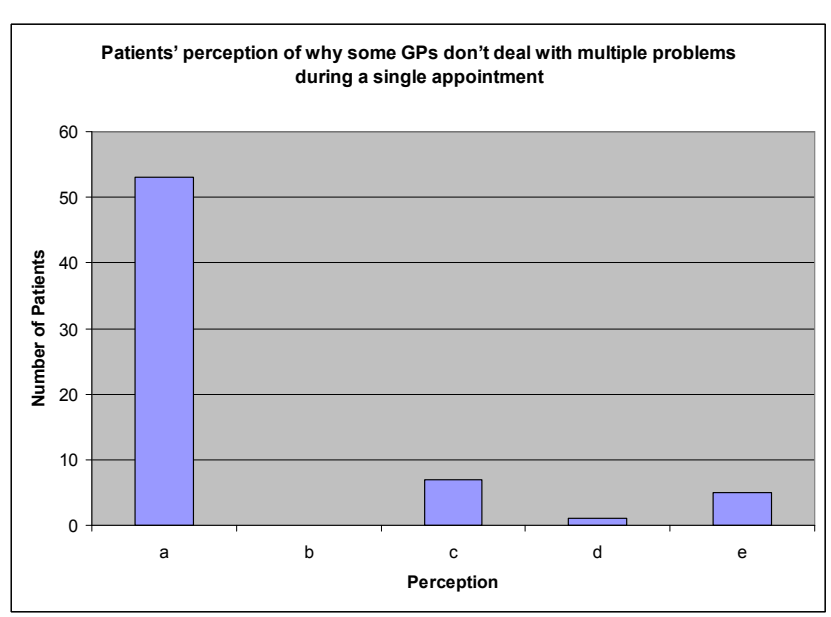

Figure 5: Patients perception of why some GP's don't deal with multiple problems during a single appointment.

\section{Key}

a) The GP wants to deal with each of your problems safely and effectively and therefore this requires the appropriate amount of time. Occasionally 10 minutes is not enough.

b) You feel that the GP is lazy.

c) All patients are equal and therefore spending significantly more time with one patient than another is not fair.

d) You think that GPs are only paid for the allotted 10 minutes and anything beyond this is 'out of the GP's own pocket'.

e) The GP is not skilled in time management and therefore cannot deal with all of your problems in 10 minutes.

\section{Discussion}

Irrespective of age or gender, most patients admitted to presenting to the GP with multiple problems approximately $30 \%$ of the time. Lack of timely access to GP appointments was the main reason cited by the majority of patients for presenting with multiple problems $[8,9]$.

The explanation that a significant majority of patients want to hear is that the GP wants to deal with each of your problems safely and effectively and therefore this requires the appropriate amount of time.

The themes arising from this research suggest that improving access to GP appointments would reduce patients presenting with multiple problems during a single consultation. Most patients do not mind if all of their problems are not dealt with during a single consultation provided effective communication skills are used by the GP to help make the patients fully aware of the reasons. The reasons and explanations should be patient, rather than GP centered [10].

For example, a GP-centered reason would be:

"Surgery is running late and unfortunately, I only have 10 minutes to deal with all of your problems today. Please could you re-book?"

A patient-centered reason would be:

"I want to ensure that all of your problems are dealt with appropriately and I want to provide you with the best standard of safe clinical service. To ensure I can devote the time that you deserve and to avoid either of us feeling rushed, could you book perhaps a double appointment so that we can discuss all of your problems further?"

A shared decision needs to be made regarding which problem is prioritized taking into account the patients' ideas, concerns and expectations coupled with the GP's clinical prioritization skills [7].

\section{Conclusion}

The findings from the research above may facilitate GP's to increase levels of patient/GP satisfaction and safety, optimize rapport, reduce complaints, help to manage time more effectively (reduce late running of appointments) and increase practice productivity.

\section{References}

1. Lichstein PR (1990) The Medical Interview.

2. Haas LJ, Leiser JP, Magill MK, Sanyer ON (2005) Management of the difficult patient. Am Fam Physician 15: 2063-2068.

3. Wilk S, Michalowski M, Michalowski W, Rosu D, Carrier M, et al. (2017) Comprehensive mitigation framework for concurrent application of multiple clinical practice guidelines. J Biomed Inform 66: 52-71.

4. O'Hara R, Beaudreau SA, Gould CE, Froehlich W, Kraemer HC (2017) Handling clinical comorbidity in randomized clinical trials in psychiatry. J Psychiatr Res 86: 26-33.

5. Siproudhis J, Chapron A, Allory E, Fiquet L, Dauguet S, et al. (2016) Patient's preferences for repeat prescriptions in general practice. Therapie 71: 579-587.

6. Mercer SW, Higgins M, Bikker AM, Fitzpatrick B, McConnachie A, et al. (2016) General practitioners' empathy and health outcomes: A prospective observational study of consultations in areas of high and low deprivation. Ann Fam Med 14: 117-124.

7. Sebo P, Herrmann FR, Haller DM (2015) How do GPs in Switzerland perceive their patients' satisfaction and expectations? An observational study. BMJ Open 5: e007085.

8. Alami S, Cottin V, Mouthon L, Desjeux D, Quessette E, et al. (2016) Patients', relatives', and practitioners' views of pulmonary arterial hypertension: A qualitative study. Presse Med 45: e11-e27.

9. Topaz M, Lisby M, Morrison CR, Levtzion-Korach O, Hockey PM, et al. (2016) Nurses' perspectives on patient satisfaction and expectations: An international cross-sectional multicenter study with implications for evidence-based practice. Worldviews Evid Based Nurs 13: 185-196.

10. Darlow B, Dean S, Perry M, Mathieson F, Baxter GD, et al. (2014) Acute low back pain management in general practice: uncertainty and conflicting certainties. Fam Pract 31: 723-32. 